\title{
O PAR COMO UNIDADE CRIATIVA REFLEXÕES SOBRE CRIAÇÃO E TÉCNICA NA DANÇA DE SALÃO
}

Fernanda Ferreira de Abreu (UFRJ)

A partir de experiência etnográfica em uma renomada academia de dança de salão do Rio de Janeiro, este artigo apresenta algumas possibilidades de análise da criação na dança de salão, considerando o par como unidade criativa e as influências do ensino e da técnica, e também indicando a valorização da "natureza" e do "popular" nesse processo de criação.

DANÇA DE SALÃO, CRIAÇÃO, TÉCNICA.

ABREU, Fernanda Ferreira de. O par como unidade criativa: reflexões sobre criação e técnica na dança de salão. Textos escolhidos de cultura e arte populares, Rio de Janeiro, v.10, n.1, p. 101112, mai. 2013. 


\section{THE PAIR AS A CREATIVE UNIT}

REFLECTING UPON CREATION AND TECHNIQUE IN BALLROOM $D A N C E$

Fernanda Ferreira de Abreu (UFRJ)

From ethnographic experience in a prestigious ballroom dance academy in Rio de Janeiro, this article presents some possible analysis of creation in ballroom dancing, considering the pair as a creative unit and the influences of teaching and technique, at the same time that it indicates the appreciation of "nature" and "the popular" in the process of creation.

BALLROOM DANCE, CREATION, TECHNIQUE.

ABREU, Fernanda Ferreira de. O par como unidade criativa: reflexões sobre criação e técnica na dança de salão. Textos escolhidos de cultura e arte populares, Rio de Janeiro, v.10, n.1, p. 101112, mai. 2013. 
Embora não haja definição cristalizada de dança de salão, podem ser indicadas algumas concepções. Por meio da observação participante que realizei em 2010 e 2011, matriculada como aluna da matriz da Escola de Dança Jaime Arôxa - localizada em Botafogo, na Zona Sul do Rio de Janeiro -, pude constatar que a expressão de sentimentos e o improviso são especialmente incentivados, em contraposição ao mecanicismo e aos "passos marcados", que, no entanto, apareceram nos relatos levantados por Virna Plastino (2006, p.48) associados à "dança de academia". Essa autora deparou-se, em um baile de um "clube tradicional de dança de salão" no Centro do Rio de Janeiro, com críticas feitas pelos frequentadores "das antigas" à forma como dançavam os que aprendiam em academias, cuja dança era considerada "uma dança 'enquadrada', 'formatada', 'repetitiva', 'competitiva', 'distanciada', 'cheia de malabarismos' e 'esvaziada de sentimentos". Já os frequentadores "das antigas" dançavam com emoção, de forma livre, e improvisavam.

Cabe, assim, ressaltar, a valorização que é dada ao improviso e à criatividade nesse tipo de dança (ALVES, 2004, p. 37). Este artigo tem, portanto, como principal objetivo analisar o processo criativo a partir de uma academia de dança de salão, buscando refletir sobre as relações entre criação e técnica. Devo esclarecer que quando falo em dança de salão na academia de Arôxa, refiro-me, de forma geral, às principais danças ensinadas nessa academia e praticadas em seus bailes: bolero, samba de gafieira, soltinho, forró, tango, salsa e zouk.

Em trabalho anterior (ABREU, 2011), parti da perspectiva da mulher (dama), que, a princípio, teria menor liberdade para criar, por ser conduzida nas danças de salão pelo homem (cavalheiro). Constatei, no entanto, que devia tratar como unidade criativa o par. Como sinalizou Jonathan Marion (2008, p. 145), "enquanto para quem está de fora, 'seguir' pode parecer menos no contexto de 'conduzir' e 'seguir', o modelo dominante enfatiza a necessidade mútua, responsabilidades e atitudes complementares". ${ }^{1}$ Nas aulas de que participei, os professores falavam sobretudo em "responder à condução", e não em "seguir". Como ressaltou uma professora: "o cavalheiro conduz, e a dama seduz e induz". A sedução é uma forma de comunicação corporal especialmente valorizada justamente por favorecer a conexão do par. Dessa forma, as reflexões que seguem consideram o par como unidade criativa.

\section{APROPRIAÇÃO DA “NATUREZA” PELA ACADEMIA}

Talvez como uma forma de se afastar do estigma de "dança mecânica" (PLASTINO, 2006), Jaime Arôxa considera-se um "decodificador da natureza hu- 
mana" e procura esclarecer esse ponto de vista que está no cerne de sua "filosofia da dança":

Isso não é minha marca, é a marca da natureza. A natureza diz que o homem tem que ficar em pé. Se ele estiver com o ombro todo largado, todo caído, ele não está na natureza. Então quando o cara está na natureza ele se parece comigo. Quantos estamos na natureza? Pouquíssimos! Levamos uma vida completamente antinatural. Então quando eu coloco na natureza, parece que é uma característica minha. Na verdade é da natureza, sou apenas um operário, sou um decodificador, um decodificador da natureza humana, só e nada mais (ARÔXA apud FERREIRA, 2009, p. 93-94).

Essa valorização da "natureza" transpareceu ao longo de toda a minha pesquisa de campo em aulas e bailes realizados na academia de Arôxa e se tornou ainda mais evidente em um evento denominado Semana da Mulher, que oferece cursos de sensualidade - durante uma semana por ano - e cujo objetivo é resgatar a sensualidade da mulher que seria inata, estaria na "natureza" da mulher, mas teria sido reprimida pela sociedade. O objetivo era que as mulheres aprendessem a ser mais sensuais não apenas na dança, mas na vida de uma forma geral.

O método de ensino de Jaime Arôxa, que se apoia no resgate de movimentos "naturais" facilitadores da expressão de sentimentos, obtém grande reconhecimento entre os praticantes - alunos e professores - de dança de salão não apenas no Rio de Janeiro, mas em diversas localidades de todo o Brasil. Como mencionei, a pesquisa foi realizada na matriz da escola de dança de Arôxa, que contava, na época, com aproximadamente mil alunos. Entretanto, essa escola possui também diversas filiais e franquias espalhadas por todo o Brasil, cujos professores costumam ir à academia de Botafogo para fazer cursos de reciclagem, normalmente promovidos durante quatro semanas por ano, duas em janeiro e duas em julho. Esses cursos também são frequentados por professores de outras academias que não levam o nome de Jaime Arôxa.

Contudo, para ser efetivamente formado em seu método de ensino, é preciso frequentar a academia de Botafogo durante período maior. Inicialmente, como bolsista, ${ }^{2}$ e depois, se realmente desejar seguir a carreira de professor de dança de salão, como assistente, monitor(a) e, finalmente, professor(a). Não há tempo predefinido para se efetivar uma promoção, em geral decidida pelo próprio Jaime Arôxa. Talvez se possa falar em média de um a dois anos em cada nível hierárquico, mas há diversas exceções. Grande parte não chega efetivamente a professor. Como assistente, porém, já se começa a dar aulas particulares, e 
como monitor, começa-se a ter algumas turmas. Muitos encaram todo esse processo como uma faculdade de dança de salão.

Parte significativa das pessoas - incluindo homens e mulheres - que se dispõem a fazer esse processo de formação pertence às classes populares e veio da Zona Norte ou do subúrbio do Rio de Janeiro, de outros municípios do Estado do Rio e de vários estados do Brasil, com destaque para os do Nordeste, sendo o próprio Arôxa oriundo de Pernambuco. Durante o período de formação e intensa dedicação ao aprendizado da dança de salão, no qual frequentam a escola de dança de segunda a segunda, muitos moram nas proximidades da academia alguns em comunidades - e dividem a moradia. Depois, é relativamente comum retornarem a suas cidades de origem para trabalhar com dança de salão, alguns, aliás, abrindo suas próprias academias de dança.

O conhecimento e experiência de dança que esses jovens (grande parte tem entre 18 e 25 anos) aspirantes a professores de dança de salão trazem de seus locais de origem, como, por exemplo, o domínio do frevo de Recife, é valorizado por Arôxa, por mais que ele não ensine esses tipos de dança. Isso provavelmente se relaciona a sua busca do resgate dos movimentos "naturais", que, por sua vez se associa, tal como analisou Roberta Ceva (2001, p. 37) em relação ao forró universitário, a uma problemática de identidade nacional marcada pela busca, por parte de segmentos da classe média, das "'autênticas raízes nacionais' e a preocupação com o resgate dos valores creditados às camadas populares, supostamente perdidos com o avanço da modernidade e a mercantilização das relações sociais". Dessa forma, é enfatizado, por exemplo, no site da academia de Arôxa, que o método desenvolvido pela escola preocupa-se em zelar por "toda essa natural espontaneidade do forró". ${ }^{3}$ Além disso, a Companhia de Dança Jaime Arôxa, da qual participam alguns de seus professores, tem em seu currículo o espetáculo Viva Brasil - uma ópera popular, "que conta, através da música, do teatro e da dança, a História do Brasil desde o descobrimento até a libertação dos escravos. Trata-se de uma homenagem às culturas negra, indígena e europeia, trazendo (...) um painel das danças brasileiras em todas as regiões". ${ }^{4}$

Essa busca das "raízes" e do "popular" também é preocupação presente em outras academias de dança. Como exemplo, Jimmy de Oliveira (apud souzA, 2008, p. 99) - ex-aluno de Arôxa que desenvolveu seu próprio método de ensino e abriu uma academia na Zona Sul do Rio de Janeiro - diz buscar "inspiração para criação de movimentos nos bailes do subúrbio (...) pois lá as pessoas realmente sentem a música, o corpo é livre para responder aos estímulos".

Percebe-se, desse modo, uma associação entre "natural", "popular" e "Iiberdade", que, por sua vez, consistiria em um atrativo para os alunos - perten- 
centes, em sua maioria, à classe média - que frequentam a escola de Arôxa e outras academias de dança de salão da Zona Sul da cidade. Essa relação merece estudo mais aprofundado, que escapa ao escopo do presente artigo, no qual me interessa apenas sinalizar que o resgate do "natural" é utilizado para favorecer o processo criativo na dança de salão, sendo, aliás, apropriado por um método de ensino que incentiva a liberdade de criação por parte dos alunos, mas, que, por outro lado, ressalta a importância da incorporação das técnicas das diferentes modalidades de dança de salão.

\section{ENSINO DA CRIAÇÃO}

Antes de apresentar algumas possibilidades de ensino da criação, cabe pontuar que, entre os alunos, o perfil é diversificado no que se refere à faixa etária (apesar de grande parte ter mais de 40 anos) e, especialmente, a ocupações profissionais. Em cada turma, há em média 15 alunos, e, normalmente, um ou dois casais (namorados ou efetivamente casados) e mais mulheres que do que homens. Para que essas mulheres tenham com quem dançar, costuma haver mais bolsistas homens participando das aulas.

Conforme discurso dos próprios professores no decorrer do trabalho de campo, a criação na dança de salão é associada ao improviso, ao imprevisível, ao surpreendente, à "viagem", a uma sensibilidade especial, particularmente com relação à música. Como disse uma professora, "cavalheiro criativo é aquele que inventa e surpreende a dama, que deixa a música inspirá-lo. Não é aquele que faz um monte de passos previsíveis".

A criação da dama também é incentivada em aulas regulares e, além disso, em aulas específicas para mulheres. Como não pode interferir ou atrapalhar a condução, observei que a criação da dama ocorre, principalmente, em dois tipos de situações: em momentos em que o cavalheiro solta a dama e deixa de conduzi-la, ou seja, quando eles efetivamente se separam não havendo contato físico entre seus corpos, o que ocorre com mais frequência na salsa; ou simultaneamente à condução, isto é, a dama responde à condução e faz algum movimento adicional que não foi conduzido, chamado de enfeite ou adorno, que normalmente é executado com os braços/mãos/dedos e/ou com as pernas/pés.

"Fazer enfeites" às vezes é considerado sinônimo de "fazer charme". Os professores até reconhecem que é possível fazer enfeites sem charme. A própria expressão enfeite remete a algo acessório e pode reduzir a ideia de criação. Porém, na concepção dos professores, não faz sentido as damas fazerem enfeites se eles não forem feitos com charme, com sensualidade. Por outro lado, fazer charme não necessariamente significa fazer um enfeite. O charme, a sensua- 
lidade e a sedução não devem estar imbuídos apenas nos enfeites, mas na dança como um todo, uma vez que favorecem a comunicação entre dama e cavalheiro durante a dança.

Como já ressaltado, a criação feminina e a masculina devem ser entendidas dentro da lógica do par. Conforme Souza (2008, p. 100) bem observou, "quando o cavalheiro se aproxima da dama, geralmente ele inicia a dança a partir de uma percepção/sensação da corporeidade de sua parceira e, nesse diálogo corporal, os dois constroem juntos uma dança de par". Nas aulas de que participei, os professores costumam incentivar os alunos a criar esse diálogo corporal, fornecendo dicas, tanto para o homem quanto para a mulher, como: "Cavalheiro, ouça a música e convide a dama para viver uma história. Com cada dama e em cada música você tem que construir uma história"; "se liga no seu par"; "se deixe inspirar pela música"; "só falta colocar o seu tempero, surpreender a dama com uma puxada mais forte"; "dama, neste momento, você pode fazer um carinho no cavalheiro".

Além disso, ensina-se como utilizar a energia sexual - que seria "natural" ao ser humano; mas reprimida pela sociedade, especialmente no caso das muIheres - para um melhor desempenho nos bailes. Tal como percebeu Citro (2009, p. 250) em relação aos bailes noturnos dos tobas na Argentina, também considero que os bailes por mim vivenciados "não consistiriam tanto em uma canalização das forças sexuais, mas essa mesma força ou pulsão subjacente no movimento corporal seria a que opera como uma das impulsoras do processo criativo". A energia sexual pode conferir, assim, novas nuanças aos movimentos dançantes, difíceis de descrever, mas sentidas por quem faz e por quem vê. Trata-se de levar essa energia para todas as partes do corpo de modo que a sedução se estabeleça entre dama e cavalheiro pela atitude corporal, expressão facial, olhar etc.

É importante pontuar, contudo, que o controle é considerado fundamental para que a energia sexual possa ser acionada em adequação com a situação social. É como se o autocontrole viabilizasse a "soltura" (ELIAS, 1994) para a criação nos bailes. Dessa forma, os professores enfatizam que os bailes são para dançar; caso se queira fazer algo além disso, é preciso sair do baile. Constatei que as aulas e os bailes se complementam, uma vez que estes são mencionados com frequência nas aulas, seja como estímulo ao aprendizado - aprender para dançar bem no baile - ou como uma forma de treinar o que foi ensinado, o que também não deixa de ser um incentivo ao aprendizado, pois os alunos que vão a bailes normalmente aprendem mais rápido. 


\section{RELAÇÕES ENTRE CRIAÇÃO E TÉCNICA}

Vimos algumas possibilidades de ensino da criação. Todavia, é importante ressaltar que o incentivo à criação ocorre, sobretudo, nas turmas mais avançadas, com no mínimo um ano de aula. Do mesmo modo, apesar de as aulas de sensualidade da já mencionada Semana da Mulher terem sido feitas por alunas em diferentes níveis de aprendizado da dança de salão, quando observei depois essas mulheres dançando nos bailes, notei que as que tinham um maior domínio da técnica de dança, eram mais sensuais dançando. Isso também depende - e muito - do par, pois as damas dançam de forma distinta com cavalheiros diferentes.

Foi surpreendente a primeira vez que observei uma professora dançando com um aluno iniciante no baile. Já a tinha visto dançando várias vezes com seu namorado, que também era professor. Como ela parecia se deixar inspirar pela música ao mesmo tempo que seduzia e inspirava seu par; como fazia enfeites que se encaixavam naturalmente na música. Contudo, dançando com um aluno iniciante, ela parecia no máximo uma aluna de nível intermediário. Era como se estivesse somente se concentrando para entender a condução e executar os movimentos de forma que um não pisasse o pé do outro. Percebe-se, assim, a influência da técnica no processo criativo, tendo em vista que saber conduzir e saber ser conduzida são pré-requisitos para que ocorra uma conexão entre cavalheiro e dama na dança. A técnica seria, portanto, a implementação de um modo de agir no corpo (MAUSS, 2003, p. 407).

Na dança de salão, as técnicas são vinculadas aos "ritmos", entendidos como modalidades de dança. A técnica do bolero é diferente da técnica do tango, e assim por diante. Os professores enfatizam que em cada ritmo o corpo deve ser utilizado de forma diferente. Uma professora contou que ela primeiro aprendeu a dançar lambada, e quando anos depois aprendeu samba de gafieira dançava esse ritmo "com o quadril da lambada". Demorou quase um ano dançando todos os dias samba de gafieira para "tirar o quadril da lambada". Ela disse isso para enfatizar que quem já dança outros ritmos fica com a "marca no corpo", com um condicionamento corporal, e que, no aprendizado de novo ritmo, é preciso implementar no corpo a técnica da modalidade que se está dançando.

A análise de Norbert Elias (1995, p. 63) dos processos de criação, em seu estudo sobre Mozart, pode nos ajudar a pensar as relações entre criação e técnica na dança de salão. De acordo com o autor, "o pináculo da criação artística é alcançado quando a espontaneidade e a inventividade do fluxo-fantasia se fundem de tal forma com o conhecimento das regularidades do material e com o julgamento da consciência do artista, que as fantasias inovadoras surgem por si mes- 
mas". De forma resumida, no caso da dança de salão, tal como percebi em minha pesquisa, o fluxo-fantasia parece relacionar-se com o jogo de sedução. As regularidades do material seriam as técnicas, os passos, as músicas etc. A consciência do artista é construída pelo artista da dança a partir de sua inserção social, que avalia sua produção diante de um conjunto de propostas técnicas e valores estéticos com os quais estabelece contato em aulas, cursos, bailes e apresentações de dança, além do convívio com outros artistas.

As noções de fluxo-fantasia, regularidades do material e consciência do artista devem ser entendidas em conjunto. De acordo com Elias (1995), quem tem consciência de artista muito segura potencializa o fluxo-fantasia e sua fusão com as regularidades do material. Certa vez, enquanto dançava bolero em um baile da escola de Arôxa com um bolsista, após já ter feito aulas de dança de salão por mais de um ano, parecia que meu par e eu estávamos em transe, inspirados, e havia um jogo de sedução. Era como se estivéssemos vivendo o fluxo-fantasia de que Elias trata. Enquanto estávamos nesse estado, meu par comentou: "nem sei o que estamos fazendo, mas estamos fazendo o que o Jaime Arôxa diz para fazer". Estávamos, portanto, criando dançando - devido ao nosso domínio das regularidades do material do bolero conforme método de Arôxa - e simultaneamente avaliávamos o que estávamos criando.

A possibilidade de tornar a fantasia comunicável é o que, segundo Elias (1995), diferencia a fantasia do esquizofrênico da fantasia do artista. Dessa forma, ao ensinar um passo de samba de gafieira, uma professora ressaltou ao corrigir os alunos: "É assim, não tem jeito. Primeiro tem que aprender a técnica, para depois poder brincar". Em outra aula, disse um professor: "Foi lindo. Vocês vão mais longe do que imaginam. Mas não esqueçam que o improviso sem o código de cada dança é superficial". Por "código" entendi que ele se referia justamente à técnica de cada dança, que viabilizaria a comunicação entre dama e cavalheiro, e também entre dançarinos e plateia, que, no caso dos bailes, é formada pelos próprios dançarinos. Sem a técnica, os movimentos criados não se configurariam como dança de salão.

Então, um par em que ambos têm grande domínio da técnica teria, a princípio, mais possibilidades de criação. Por outro lado, a incorporação da técnica do tango, por exemplo, não é suficiente para criar dançando tango. Por isso, os professores também incentivam os alunos a se deixar inspirar, a utilizar a energia sexual levando-a para as demais partes do corpo, a "viajar na música", a resgatar o "natural" em seus movimentos etc. Talvez essa "marca da natureza" possa ser relacionada ao que Elias (1995, p. 56) chamou de processo de sublimação. Diferentemente do que ocorre no caso da repressão, "há processos de sublimação 
pelos quais as fantasias humanas, convertidas em criações musicais [no caso de Mozart], podem ser despojadas de sua animalidade sem necessariamente abandonar sua dinâmica elementar, seu ímpeto e força". Parece ser justamente essa "dinâmica elementar" que Arôxa busca ao se considerar um "decodificador da natureza humana".

As três dimensões propostas por Elias (1995) não abarcam, contudo, a interação no momento da criação, o "aqui e agora" da arte, que é particularmente importante no contexto de performance dos bailes e que se aproximaria da noção de fluxo (flow), apresentada por Victor Turner $(1982)^{5}$ para se referir à experiência de um momento único, em que a ação está concentrada em um campo limitado de estímulo. Essa noção de fluxo pode ser aproximada das experiências de transe, relatadas por praticantes da dança de salão, e que eu mesma vivenciei durante a pesquisa, como relatado. É importante considerar, portanto, que a dança é arte performática, sujeita a variações a cada vez em que é desempenhada, o que faz com que seu contexto de desempenho seja especialmente relevante para a dança produzida (SEEGER, 1977).

Apesar de os bailes realizados pela academia pesquisada ocorrerem no mesmo espaço físico das aulas, eles têm maior duração, contam com mais participantes, sob iluminação mais fraca e som mais alto. Podemos entender, então, a aula como o espaço propriamente da técnica ou como o espaço para formação do corpo em uma determinada técnica. Vimos que a criação é estimulada nesse espaço, porém os alunos vão para as aulas principalmente para aprender a técnica da dança, e não propriamente para criar. Há preocupação em executar os movimentos da forma como foram ensinados. Assim, no baile haveria, em princípio, mais liberdade e maiores possibilidades de criação. Como também notou Mariana Massena (2006, p. 83), “nos bailes, cada casal é responsável por sua própria atuação diferente das aulas onde existe supervisão". É interessante observar como a própria entrada no baile, por mais que seja no mesmo espaço físico das aulas, parece estimular e até mesmo viabilizar o processo criativo. É nos bailes que a mulher efetivamente vira dama, e o homem, cavalheiro; o par, de fato, torna-se par, e as possibilidades de criação, aliadas ao jogo de sedução, parecem ser intensificadas.

\section{CONSIDERAÇÕES FINAIS}

De forma a resumir o que é de fato fundamental para a criação na dança de salão no contexto por mim analisado, destaco a combinação entre técnica e sedução - imbuída da energia sexual que estaria na "natureza" do ser humano -, 
elementos considerados importantes para uma comunicação fluida entre dama e cavalheiro, que se potencializa na situação do baile.

O objetivo foi indicar, a partir de minha experiência etnográfica, possibilidades para se pensar a criação na dança de salão, enfatizando, principalmente, a influência da técnica e de um método de ensino que se apropria da valorização da "natureza" associada ao "popular". Espero que esta análise, ainda que sucinta, possa ter indicado as contribuições que estudos da dança de salão no Rio de Janeiro podem gerar para discussões mais amplas sobre a criação no âmbito dos estudos sobre dança, visto que se trata de tema ainda muito pouco explorado.

\section{REFERÊNCIAS BIBLIOGRÁFICAS}

ABREU, Fernanda Ferreira de. A mulher na dança de salão: sociabilidade, ensino e criação. Dissertação (Mestrado) - Programa de Pós-graduação em Ciência da Arte, Universidade Federal Fluminense, Niterói, 2011.

ALVES, Andréa Moraes. A dama e o cavalheiro: um estudo antropológico sobre envelhecimento, gênero e sociabilidade. Rio de Janeiro: Editora FGV, 2004.

CEVA, Roberta Lana de Alencastre. Na batida da zabumba: uma análise antropológica do forró universitário. Dissertação (Mestrado) - Programa de Pósgraduação em Antropologia Social/Museu Nacional, Universidade Federal do Rio de Janeiro, Rio de Janeiro, 2001.

CITRO, Silvia. Cuerpos significantes: travesías de una etnografía dialéctica. Buenos Aires: Biblos, 2009.

CSIKSZENTMIHALYI, Mihaly. Flow: studies of enjoyment. University of Chicago: PHS Grant Report, 1974.

ELIAS, Norbert. O processo civilizador: uma história dos costumes. V. 1. Rio de Janeiro: Zahar, 1994.

. Mozart, sociologia de um gênio. Rio de Janeiro: Zahar, 1995.

FERREIRA, Jéssyca Monteiro. Dança de salão: novas configurações do campo. Monografia (Graduação) - Departamento de Arte Corporal/Centro de Ciências da Saúde, Universidade Federal do Rio de Janeiro, Rio de Janeiro, 2009.

MARION, Jonathan S. Ballroom: culture and costume in competitive dance. Oxford/New York: Berg, 2008.

MASSENA, Mariana. A sedução do brasileiro: um estudo antropológico sobre a dança de salão. Dissertação (Mestrado) - Programa de Pós-graduação em Sociologia e Antropologia/Instituto de Filosofia e Ciências Sociais, Universidade Federal do Rio de Janeiro, Rio de Janeiro, 2006.

MAUSS, Marcel. As técnicas do corpo. In: Sociologia e antropologia. São Paulo: Cosac Naify, 2003. p. 399-423.

PLASTINO, Virna Virgínia. Dança com hora marcada: uma etnografia da atração social em bailes de salão no Rio de Janeiro. Dissertação (Mestrado) - Progra- 
ma de Pós-graduação em Antropologia Social/Museu Nacional, Universidade Federal do Rio de Janeiro, Rio de Janeiro, 2006.

SEEGER, Anthony. Por que os índios suya cantam para as suas irmãs? In: VELHO, Gilberto (org.). Arte e sociedade: ensaios de sociologia da arte. Rio de Janeiro: Zahar, 1977. p. 39-63.

SOUZA, Maria Inês Galvão. As novas configurações dos espaços de lazer de dança de salão da cidade do Rio de Janeiro: uma análise das performances do palco da vida. In: MELO, V. A.; ALVES JÚNIOR, E. D; BRETAS, A. (Org.). Lazer e cidade: reflexões sobre o Rio de Janeiro. Rio de Janeiro: Shape/Faperj, 2008. p. 89-103.

TURNER, Victor. Liminal to Liminoid, in play, flow, and ritual: an essay in comparative symbology. In: From ritual to theatre: the human seriousness of play. New York: PAJ Publications, 1982. p. 20-60.

\section{NOTAS}

1 Nesta e nas demais citações em língua estrangeira a tradução é da autora.

2 Os bolsistas - homens e mulheres - realizam diversas aulas sem pagar; em troca, auxiliam os alunos nas aulas e têm que cumprir carga horária mínima, acordada com os professores. São selecionados através de audição, não havendo pré-requisito específico, a não ser disponibilidade de tempo para participar das aulas.

3 http://www.jaimearoxa.com.br/turmas. Acesso em 16.05.2013.

4 http://www.jaimearoxa.com.br/produtora. Acesso em 16.05.2013.

5 Turner (1982) se baseia em Csikszentmihalyi, 1974.

Fernanda Ferreira de Abreu é doutoranda em antropologia social pelo Museu Nacional - UFRJ e mestre em ciência da arte pela UFF (2011).

Recebido em: 06/02/2013

Aceito em: 17/04/2013 